\title{
Del documento de los Sabios a la Práctica Docente
}

\author{
HILDA MARINA BOHORQUEZ L. \\ Coordinadora Práctica Docente \\ Facultad de Educación
}

En el documento de los Sabios: volver aprender a convivir y a entrar "COLOMBIA: AL FILO DE LA voluntaria y eficazmente en un nuevo OPORTUNIDAD" se encuentran ideas y comentarios muy importantes relacionados con la necesidad de apuntar a cambios profundos en el sistema Educativo, los cuales pueden y deben ser tenidos en cuenta por las Facultades de Educación.

Aspectos que tienen que ver con éstas se enmarcan en:

a) "Un cambio en el pensamiento y estilo de trabajo de todos los individuos que pertenecen a una organización (conjunto de personas, procesos y recursos materiales y de conocimiento, e información estructurado y ordenado deliberadamente para el cumplimiento de una tarea específica) en cuanto a aprender a aprender; aprender a vivir en paz con nosotros mismos y con la naturaleza, a desarrollar todo nuestro potencial humano y a crear participativa y colectivamente"

b) "Una mayor integración entre los niveles primario, secundario y postsecundario y entre el mundo escolar con el mundo laboral y productivo, tal que se evite la sensación de frustración e irrelevancia experimentadas ante una educación ajena al alumno".

c.) "La necesidad en todos los estamentos de retomar la discusión sobre valores, de intensificar la formación ética y cívica, de espacio social".

d.) "La importancia de recuperar la dignidad y la autoestima de los docentes como competencia de ellos mismos, bajo el apoyo amplio del Estado y de la sociedad civil".

e.) "La necesidad de desarrollar estrategias y acciones de apoyo a los estudiantes que lo soliciten y a los menos aventajados para disminuir la probabilidad de deserción del respectivo nivel escolar".

f.) "Transformar las actuales facultades de educación, tendiendo a recobrar el estatus del docente como profesional e intelectual de alto nivel".

EL COMITÉ DE PRACTICA DOCENTE DE LA FACULTAD DE EDUCACIÓN , en la actualidad conformado por los profesores: Julian Colunje (Administración Educativa), Angela Rivera (Lingüística y Literatura), Humberto Alvarado (Lenguas Modernas), Sucell Ardila (Educación Preescolar), Liberio Salazar (Artes), Orlando Salinas (Educación Física), Helga Truque (Representante Dpto. de Psicopedagogía), Nohora Ortega (Representante de los estudiantes practicantes) e Hilda Bohórquez 
(Matemáticas y Física), viene desarrollando su trabajo apuntando a contribuir en el logro de los aspectos anotados en los literales anteriores.

\section{Entre las gestiones adelantadas están:}

1. El ordenamiento en todas las actividades inherentes al proceso de la práctica docente a través de la formulación participativa, crítica y colectivamente de Reglamentos coherentes, aplicables y similares entre sí para cada uno de los programas.de formación docente de la Facultad de Educación. Además de la formulación está la aplicación rigurosa de los mismos pero en forma comprensible dentro de las posibilidades humanas exigiendo las responsabilidades y ética pertinentes a todas las personas involucradas if e interrelacionadas dentro del proceso de la práctica.

2. La adaptación del desarrollo de la práctica docente a las actividades propias de las instituciones escogidas como Centros de Práctica en cuanto a sus calendarios y exigencias tendientes a dar cumplimiento a la Ley 115.

3. El facilitar al practicante la vivencia de situaciones propias del ejercicio docente mediante su vinculación al centro de práctica en tiempo y actividades que procuren una permanencia equilibrada en beneficio tanto al Centro como al practicante.

4. La organización y realización de conferencias, talleres, paneles, etc. a lo largo de cada semestre, tendientes a complementar la formación del estudiante futuro educador en cuanto a aspectos legales, éticos, etc. que permitan simultáneamente: generar el espíritu de trabajo participativo y colectivo, acercar al estudiante hacia el mundo laboral, aprender a convivir, concientizarlo sobre su estatus como educador etc. Se debe resaltar acá que las diferentes actividades se han podido realizar gracias a la participación, sin ninguna contraprestación económica, sólo por su deseo de contribuir a la formación de los estudiantes, de personas como: Fernando Perdomo, Miller Dussán, Julian Colunje, María Nain Carrillo, Nora Chávarro, Antonio Iriarte, Margarita Chacón, Helga Truque, etc.

5. La vinculación de la práctica docente en la solución de problemas y necesidades manifestadas por los centros de práctica como: -Organización y realización de cursos de reforzamiento académicos en las áreas de español, inglés, matemáticas y física; -Preparación de estudiantes para participar en olimpiadas de matemáticas, fisica y educación fisica; -Orientación a madres en programas comunitarias de atención a la niñez; -Alfabetización en sectores rurales $y$ urbanos, cuyas condiciones de superación son difíciles; Participación en el programa Educativo para la paz y la reconciliación nacional (Reinsertados); -Organización de grupos musicales y de rajaleñas en centros educativos y comunas; Organización y realización de muestras de artes:; -Orientación de trabajos para muestras de ciencias; -Orientación en la elaboración de Proyectos Educativos Institucionales para algunos Centros Educativos.

Así como se anotan las gestiones que llevan al alcance de nobles y altos ideales como los planteados en el documento de los Sabios, para los cuales se requieren cambios radicales de actitudes, es preciso decir a manera de crítica constructiva que hay aspectos en los que por falta de liderazgo o compromiso total, en algunos programas, se presentan aún anomalías que de no corregirse pueden entrabar el proceso de cambio que se desea adelantar:

- Falta de cumplimiento en sus funciones por parte de algunos asesores, en especial 
en la orientación de documentos requeridos en el desarrollo de la práctica docente.

- Demora en la solución concreta, correcta y oportuna de solicitudes hechas por los estudiantes, en el organismo al cual se han enviado.

- Falta de un mayor contacto del Coordinador con los centros de práctica en los que han ubicado a los practicantes de su respectivo programa.

Finalmente, cualquiera que sea el Decano elegido, lo que importa para hacer posible el alcance de lo planteado, es el apoyo pòr parte del mismo en forma decidida, a los proyectos, propuestas y actividades que emprendan los estamentos involucrados en el proceso de la Práctica. Son muchas más las acciones que el Comité de Práctica de la Facultad, con la participación de todos los profesores asesores de cada programa, de profesores de las didácticas generales y especiales y de los estudiantes practicantes, podría emprender para apuntar a alcanzar las metas sugeridas en el documento de los Sabios, tendientes a mejorar la Educación a nivel local, regional y nacional permitiendo así "dar a Colombia la oportunidad óptima para un futuro mejor en un mundo que discriminará a las personas según sus capacidades cognitivas, culturales y organizacionales y a la final conducirla hacia el mejoramiento cuantitativo $y$ cualitativo de la vida". 